\title{
Be Part of the Chemotherapy Community!
}

\section{Editorial by the Incoming Editor-in-Chief}

\author{
Fritz Sörgel , Editor-in-Chief
}

Since its introduction in 1959, Chemotherapy has had three editors, the founding editors H.P. Kümmerle and P. Rentchnick, and Hans Schönfeld, who took over in 1968. $\mathrm{He}$ retired as Editor-in-Chief at the end of 2001. Hans Schönfeld did an excellent job in maintaining the role of Chemotherapy in publishing relevant work in chemotherapy. It is planned that the journal will keep its role as - to my knowledge - the only scientific journal that has successfully focussed on all aspects of chemotherapy, including fighting infectious pathogens as well as malignant processes. In these areas, publications from the journal have become key and 'state-of-the-art' papers. Chemotherapy has also managed to keep its global readership. In this way, Hans Schönfeld has been paving the way for the journal to grow, develop and continue its leadership in its focus areas. Thanks a lot Hans Schönfeld!

Scientific publishing in general faces many new and exciting challenges today and so does Chemotherapy. To meet these challenges, the publisher has given me the liberty to make any necessary changes to meet today's needs in scientific publishing. This is greatly appreciated and places a great burden on my professional life. Part of the burden will also be given to the new members of the editorial board. In an age where nothing else seems to count except impact factors of articles and journals, it must of course be a primary goal of the new Editor-inChief and his colleagues to increase that factor. We consider this task also as a service and reference to the authors who give away the best they have: their scientific results. They must know that their hard work is in excellent hands and in ones that form a clear and fair reviewing

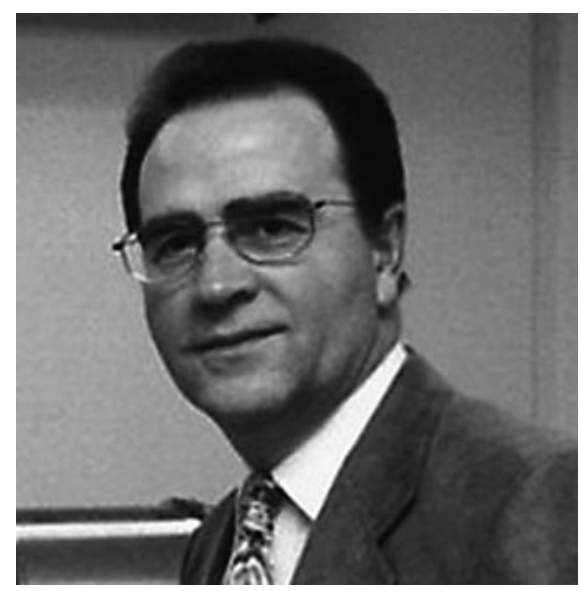

system. Just as a small business can serve the customer better, a smaller journal like Chemotherapy should be able to provide almost 'personal service', and it will be shown in the very near future what I mean with this, that is, the Chemotherapy Community.

However, the Editor-in-Chief and his board can only help to achieve that goal of higher impact factors by providing the right platform and by assisting authors to write. It must be in any author's interest to help improve and contribute to this positive development by submitting articles of high quality. The Editor-in-Chief and his board will help publish those articles of high quality particularly quickly. And to achieve this, we will collaborate as colleagues and partners using electronic communication. In

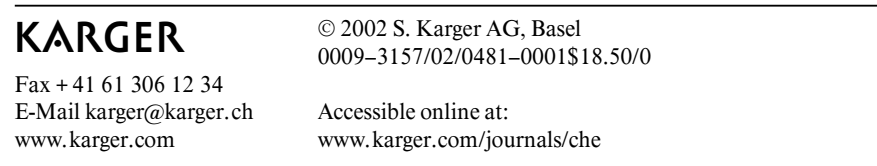


the months to come, the editorial board will thus be subjected to a reorganization with regard to the number and competence of its members, but more importantly its structure and working procedures.

The review process will be made as transparent as possible. Submitting authors shall have a clear view of what the journal stands for and what standards are to be applied. Authors from countries where it may be difficult to publish internationally will get help in submitting their papers to the editorial board on a trial basis. Underdeveloped and developing countries will have the opportunity to publish papers relating to relevant work from their countries. Here I am referring in particular to clinical studies and studies that relate to country-specific issues like bacterial resistance or local drug use. The industrialized world may learn a lot from such studies and may - on the other hand - be invited to help resolve those countries' problems.

Recently, a debate arose as to how industry-sponsored work should be published and what restrictions should be used. Chemotherapy will be committed to objective information and objective review of submitted articles. As much as the journal will be devoted to this goal, it also acknowledges the legitimate right of the manufacturer to publish its work and opinion and to introduce its products to the medical community. Again, an objective and transparent review process will help achieve this goal.

One aspect of modern drug development concerns me considerably. It seems that in a number of cases, it has been the stockholders and their money for whom a new drug is developed, rather than the patient. Instances have been reported where even in clinical studies, the protocol review process failed and patients or even healthy volunteers suffered. The scientific journals and their boards must remain a bastion against biased reporting or even falsification of data. Some 'new ways' of drug development may lead to 'overinterpretation', biased views, incorrect handling of data and even fraud. If prestudy procedures fail, it must be poststudy processes - like scientific publishing - that prevent the worst.

Other new features of Chemotherapy to be developed in the months ahead will include the fast-track review process mentioned above, the public review process and forums on each paper published in the journal. Reviews are most welcome and we will try to publish one review per issue, starting this summer. Open forum papers will be the next step, after the paper is out but also for public reviews as the 'public editorial process'. Other forums on hot topics will be introduced and thus help us to invite authors to write articles on these issues as either reviews or original papers. Also, the tricky matter of providing original data to the reader will be addressed. Many of these new ideas will be inaugurated during this year but the dynamic process of adaptation of the journal to new developments will be a permanent and continuous one.

Thanks to a technology-driven and open-minded publisher, the future looks bright for our journal in terms of using the latest IT technologies to improve the process of making reliable research work rapidly available to any corner of the world, but not at the cost of quality and reproducibility. The readers of Chemotherapy are invited to participate in this process and help to make Chemotherapy 'their journal', a greatly appreciated and wellrespected one. The new Editor-in-Chief is also willing to make himself available for authors and readers for help at any time at this global E-mail address: editchemotherapy@aol.com, 'The Chemotherapy Community'.

We further invite you to become a Chemotherapy reviewer. If you are interested in reviewing submitted papers according to the standards mentioned above please send your curriculum vitae, list of publications and other documents that qualify you for this important task to the Editor-in-Chief (preferably by E-mail to editchemotherapy@aol.com).

Several new members of the editorial board have been nominated by me and have agreed to participate in achieving these goals. I wish to thank the following great scientists from all over the world for accepting this role (in alphabetical order): Stefan Horkovics-Kovats (Kundl, Austria), Michael Jacobs (Cleveland, USA), David Nicolau (Hartford, USA), David Nix (Tucson, USA), Leonid Stratchounsky (Smolensk, Russia) and Vitan Vlahov (Sofia, Bulgaria). The former members of the board, except those who retired at their own wish, will also be part of the future editorial board and their experience will be greatly appreciated.

As the new editor, I intend to represent quality and speed of publication, integrity of the review process and open-mindedness to the use of new technologies that may be instrumental in publishing and improving the communication between scientists, physicians and pharmacists, namely by web-based systems. In addition, I stand for ethical medical research that is primarily performed to improve patient care, either directly by results from clinical research or indirectly from basic research. I wish to thank Karger Publishers for choosing me for this great project. 